\title{
EVALUATION, DEMANDING SITUATIONS AND POSSIBILITIES OF BIG DATA AND CLOUD COMPUTING
}

\author{
Dr. Liladhar R Rewatkar \\ Department of Computer Science \\ Prerna College of Commerce, Nagpur, MS, India
}

\author{
Dr. Ujwal A Lanjewar \\ Department of MCA \\ VMV College, Nagpur, MS, India
}

\begin{abstract}
This paper gives the profound appraisal of huge information (Big Data) and Cloud Computing. These fields have advanced phenomenal weight over the most present years and capacity pulled in numerous mechanical association examination and gatherings.
\end{abstract}

In present day ICT universes, there are two most significant fields are utilized for putting away and recovering information, these are Big Data (enormous data) and distributed computing. Each are uncommon on account of the Big information speaks to data inside type of literary substance, previews, pix, video cuts while distributed computing is framework concerning equipment, stockpiling, programming system and verbal trade instruments. The huge information is included 4 significant components - Extent (volume), (speed), Range (assortment), and Veracity causes the data to oversee and examination requesting conditions for the conventional actualities stockrooms.

Simultaneously as each are blended, it gives awesome impacts for the clients. Utilizing distributed computing, enormous information might be handled on our non-open PC structures and workstations pretty easily. Each of those give a solid arrangement this is adaptable and pleasing for huge insights and boss investigation. The venture investigation addition can offer enormous favorable circumstances in now daily's reality. Every one of the records sources develop as without issue close by in each test of ways of life. This research paper talks about the key considerations of distributed computing and enormous data, their similarity with each unique and the manner in which they are useful for organizations around the region.

\section{INTRODUCTION}

The expanding number of development of computational property creates a top notch amount of data every day. Data is to be had in bounty anyway it's miles difficult to remove valuable insights. The very great interpersonal interaction web site, Facebook, serves 0.57 trillion page hits in a month, stores 3000 million new pics every month and handles 25 billion sections of substance [1]. The in vogue ideal models which incorporate distributed computing, network registering, apportioned structures have get right of section to enormous bits of computational power by method for the collection of possessions and they offer an unmarried instrument photo see. Distributed computing transforms into a vigorous stage for performing tremendous scale unrivaled registering. The best thought process of these figuring innovations is to supply a component or goals for taking care of enormous realities.

Predictable with Gartner's Hype Cycle for developing innovation, Big Data and Cloud Computing have been perceived as these days creating technology [2]. Distributed computing is an in vogue worldview that gives foundation for figuring and preparing of a wide range of records assets. The innovation put together totally for the most part with respect to the cloud had been gone with to address huge bits of data.

Totally in light of the fact that the cloud is creating consistent, we additionally are seeing a blast of records all through the web. Web based life might almost certainly be entirely reality exceptional around the world, in which every advertiser and not strange customers produce heaps of measurements every day. Companies and establishments likewise are creating data on consistently that may at last end up hard to control. Test the ones major certainties ages inside the last five years;

- 2.3 Trillion Gigabytes of actualities are produced every day.

- 43 Trillion Gigabytes of actualities can be produced with the guide of 2020 .

- Lot of gatherings in the North American country don't have any bounty considerably less than a 100 Terabytes $(100,000$ Gigabytes) of put away certainties.

Those intemperate volumes of information present a venture to the cloud condition. The best approach to control and quiet the substance of these insights in inclination to just stacking it?

The blend of cloud computing and massive information is the response for this [3]. In blend, they give an answer this is both versatile and pleasing for enormous data and undertaking association investigation. Every one of the insights resources 


\section{International Journal of Engineering Applied Sciences and Technology, 2019 \\ Vol. 4, Issue 4, ISSN No. 2455-2143, Pages 100-104 \\ Published Online August 2019 in IJEAST (http://www.ijeast.com)}

rise as results accessible. Every everyday issue will take get a kick out of these realities.

\section{OVERVIEW OF BIG DATA AND CLOUD COMPUTING TECHNOLOGIES}

\section{A. Cloud Computing-}

Cloud computing is a fresh out of the box new model for permitting inescapable and good network get right of section to a mutual pool of hotspots for figuring wherein explicit contributions which incorporates servers, stockpiling, organize bundles, and records focus fabric are added to clients gadgets and frameworks over the web and various processing contributions which can be appropriate away provided with least endeavor and backer organization communication [4]. In distributed computing, the word cloud represents the net. Thusly, it's miles a period wherein the transportation of figuring property takes area over the web. Distributed computing makes a solid purpose of developing the quality of calculation to the volume that several a huge number of directions might be completed with regards to second.

With the short improvement of registering time and the satisfaction of the remote system, the assets have become an awe inspiring arrangement increasingly powerful and are to be had universally. Distributed computing is one form that has empowered the supply of sources like CPU, stockpiling, and numerous others. Too known administrations that might be leased and propelled by means of the client's conventional with their call for through the net [6]. The basic tendencies of a distributed computing form as characterized through utilizing [4] [7] may be:
- On - call for self - bearer- The clients who are approaching the cloud contributions can interface with the cloud to play out a few obligations like structure and sending applications, managing, and planning. Processing skills all in all with way quality, stockpiling, virtual machines, etc., are accessible to the person as and keeping in mind that ideal without the necessity for human affiliation.

- Broader Network Access- Cloud computing administrations offer openness to the answers for business venture organization control techniques through cell phones, containers, workstations, and work environment PC frameworks. Those devices can be utilized through a smooth online get admission to factor at wherever. Big community gets right right of entry to encompass public clouds, personal clouds, or a hybrid deployment.

- Aid Pooling- Cloud oversee sellers make a common pool of assets this is available with the helpful asset of everyone and after that these assets are to be must be used by a huge broad sort of clients through that pool. It utilizes multitenure in which the sources are designated and de-assigned to the characters accessible if the need arises for, progressively.

- Fast Elasticity- The designation of things is flexible that changes promptly and fast unfaltering with name for. Buyer can scale out the benefits by means of liberating them returned back to the Cloud that isn't wanted any longer. Along these lines, they could increase additional things with the guide of over again scaling in their useful asset necessities.

- Measured Provider- Beneficial guide usage is observed by method for the utilization of estimating CPU hours, stockpiling zone use, data transmission use, and parcel of

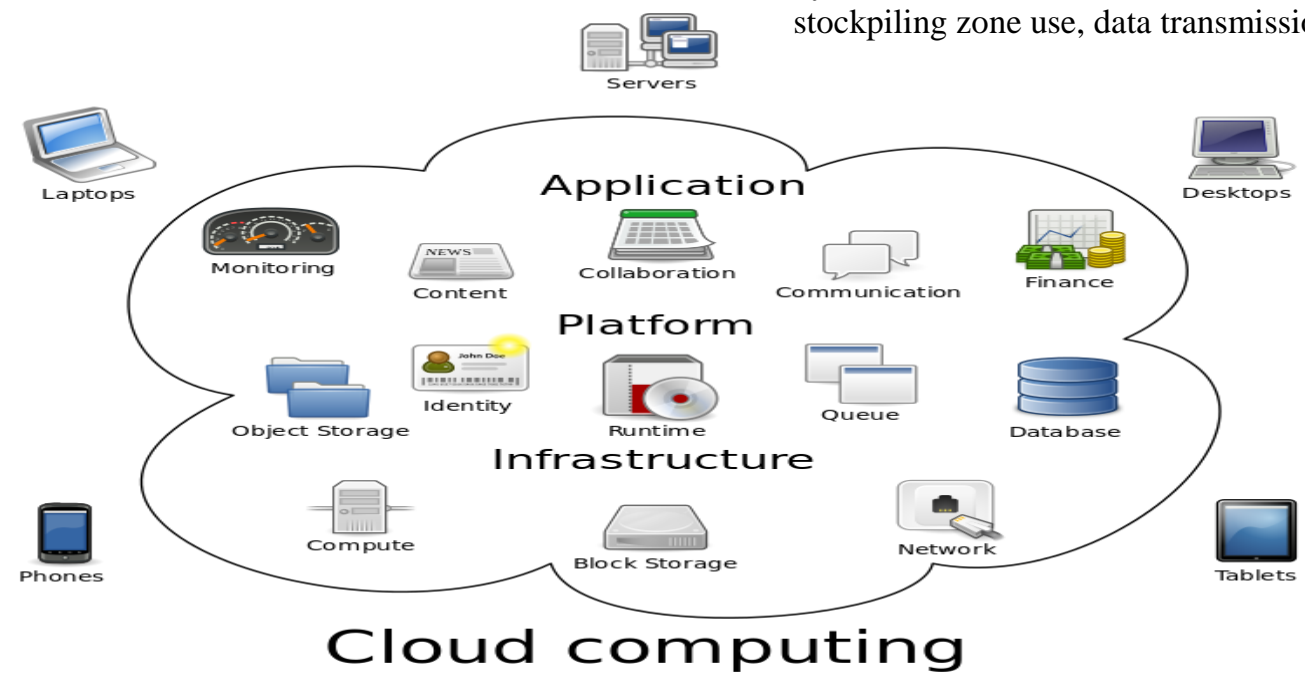

Fig. 1. Cloud Computing Environment [5] 


\section{International Journal of Engineering Applied Sciences and Technology, 2019 \\ Vol. 4, Issue 4, ISSN No. 2455-2143, Pages 100-104 \\ Published Online August 2019 in IJEAST (http://www.ijeast.com)}

others. The above-expressed measurements are completed to every one of the mists; anyway each cloud gives benefits in accordance with their hierarchical protection with stand-out degrees of deliberation, introducing a chance to the administration.

The arrangement of the cloud office is to control the cloud and resources accessible in the cloud, rent the property from one cloud to a couple of unique to serve the spare you-clients. The developing improvement of distributed computing has made the multi-nationwide organizations like Google, Rackspace, Amazon, Microsoft, etc. To give cloud structures to profit by this new worldview.

\section{B. Big Data}

Big Data demonstrate the measurements gadgets which is likely entirely monstrous and convoluted. The customary data preparing applications are inadequate to adapt to gigantic measurements. The timeframe "enormous data [8]" is idea to be created from the net web site page assessment. Depicting huge actualities as basically a phenomenal amount of data is essentially no longer adequate, neither advocated. The records speak to a great assortment; and it could be prepared in top notch systems, depending at the investigation. Steady with Gartner: "Huge Data is unbalanced amount, unreasonable pace, and additionally unnecessary assortment records things that require new sorts of handling to allow prevalent choice making, observation disclosure, and way streamlining" [9]. The 3 expresses that connote colossal insights [8] [10] are:

Degree alludes back to the regularly creating insights developing past terabytes (as an occurrence exchange records, sensor measurements, and bunches of others.).

Range alludes back to the measurements that is amassed from heterogeneous assets which consolidates machines, sensors, and loads of others. Making it hard to oversee (for instance messages, sound visuals, literary substance archives, etc.)
Speed alludes back to the pace of the age of ongoing actualities and besides the way that how quick it wants to be prepared. The records can end up being old in an extremely brief time

Variability and Veracity are the two first class measurements that square level of certain in regards to monstrous information.. Inconstancy characterizes the irregularity of insights at perfect timeframes, along these lines hampering the unwavering quality and ground-breaking control of measurements; even as veracity alludes to the attributes of the data this is being caught. The assessment of the records depends upon at the measurements caught.

With the quick improvement of systems administration innovation and the developing style of distributed computing, colossal data are truly intensifying in every one of the areas of designing age. A lot of data is delivered relentless with day. An overview perceived that ninety level of the general data inside the global transformed into created inside the most recent 2 years [11]. Guaranteed inclination making depends upon at the precision of enormous records which thus brings about more prominent operational all inclusive by and large execution, diminished expenses, and diminished dangers. The unprecedented volumes of insights require unequivocal measurements assessment and forecast stage to procure short reaction and genuine time type for said ahead of time monstrous records.

\section{OPPORTUNITIES IN BIG DATA AND CLOUD COMPUTING}

Cloud computing and big data is a totally one of a kind total since it gives an answer this is versatile and pleasing for huge data and association examination. Inside the age of insights innovation, every one of the measurements effects are without issue accessible, and everything of ways of life can advantage from this actualities [12] [13]. Investigate those gifts in detail:

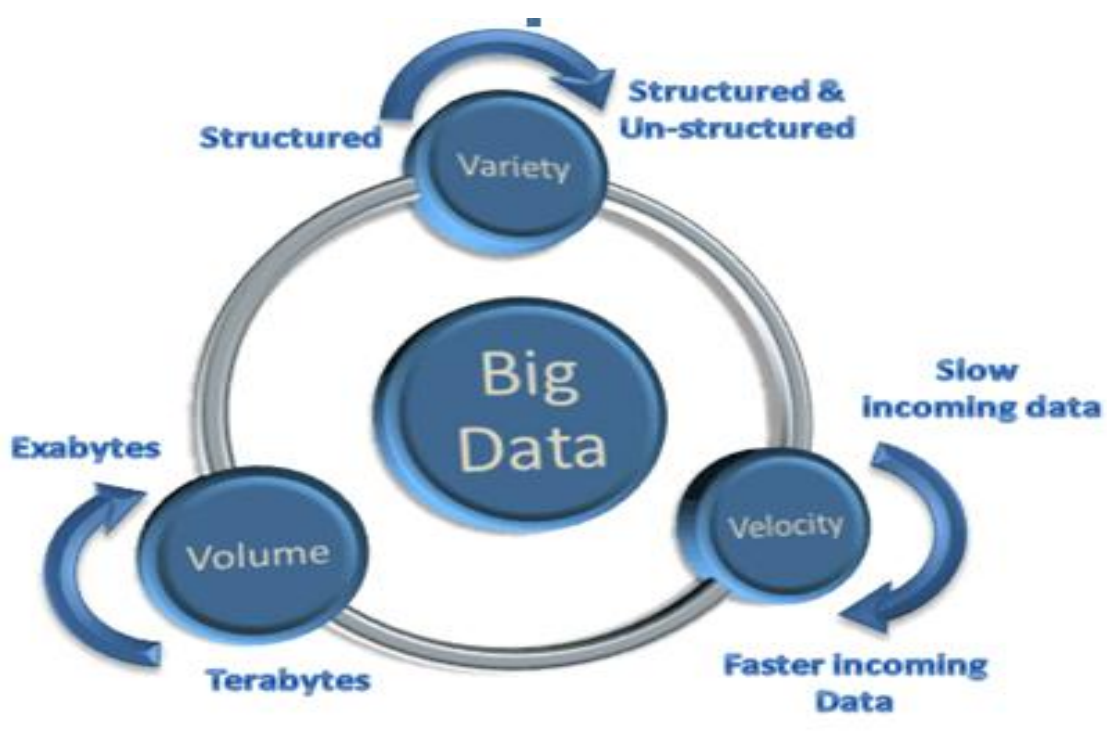

Fig 2. Big Data Characteristics [18] 


\section{International Journal of Engineering Applied Sciences and Technology, 2019 \\ Vol. 4, Issue 4, ISSN No. 2455-2143, Pages 100-104 \\ Published Online August 2019 in IJEAST (http://www.ijeast.com)}

Spryness: The normal framework of putting away and adapting to data is directly demonstrating to be increasingly slow intense to control. It might take a long time to for all intents and purposes introduce and run a server. Distributed computing is directly here now, and it might offer your business organization undertaking with every one of the things you need [14]. A report will tell your office to extremely close to home masses of virtual servers and make them run flawlessly in lovely depend of mins.

Affordability: Cloud computing most likely surprisingly positive development for an organization that wants to individual refreshed innovation underneath funds. Associations will choose what they require and pay coins for it as they will go. The property required to control Big Data are easily and they don't value tremendous bucks [14]. The things required to control Big Data are easily accessible and they don't esteem tremendous greenbucks [14]. Sooner than the cloud, organizations used to make speculations huge aggregates of money in putting in it divisions after which paid additional cash to protect that equipment exceptional. Presently the organizations can have their huge records on offsite online servers or pay best for capacity zone and quality they utilize each hour.

Records System: The blast of E learning results inside the issue of handling it. Online life without anyone else's input creates a heap of unstructured, tumultuous insights like tweets, posts, pictures, motion pictures and websites that won't be prepared beneath an unmarried heavenliness. With huge data investigation structures like apache hadoop, based absolutely and unstructured data can be prepared [14]. Distributed computing makes the entire methodology considerably less unpredictable and to be needed to nearly nothing, medium and immense organizations.

Feasibility: Big Data Analytics need new methodology wants for huge measurements gadgets. The call for handling this measurements can increment or fall whenever of the year, and the cloud condition is the best possible stage to meet this venture. There's no requirement for conveyed framework in light of the fact that the cloud can offer most extreme answers in SaaS models.

\section{CHALLENGES: BIG DATA AND CLOUD ENVIRONMENT}

Unquestionably as Big Data has furnished organizations with terabytes of skill; it's also given an issue of managing these records underneath an enormous system. How to explore the huge standard of perceive the best approach to require out totally the most extreme helpful bits? Considering the ones gigantic volumes of data much of the time transforms into a hard mission as appropriately [16].

Moving immense unit of data with over the top speed- In the exorbitant beat availability age, moving huge units of realities and providing the records expected to get appropriate of get right of passage to it, is additionally a problem. Those colossal gadgets of data as often as possible bring delicate information like financial assessment/plastic numbers, addresses, and unquestionably unique information, raising actualities security concerns.

Protection Protection issues inside the cloud are a main inconvenience for organizations and cloud bunches today. It feels like the aggressor's region unit persistent, and that they hold designing new techniques to discover get passage to factors in a gadget. Select issues incorporate ransomware, which profoundly impacts a partnership's fame and property, refusal of transporter assaults, phishing strikes, and cloud misuse.

Insecure interfaces- Globally, $40 \%$ of organizations proficient a ransomware occurrence inside the course of the previous a year. Every client and cloud suppliers have their level of dangers included while concurring on cloud arrangements. Unreliable interfaces and slanted API's will show cherished certainties to programmers, and those programmers can abuse those data for the wrong reasons.

A couple of cloud designs locale unit in spite of reality that in the preparing degree and smooth programming program programming gadget isn't totally custom fitted for distributed computing. Data acts is moreover a major inconvenience which objectives records focuses to be towards an individual than a guarantor.

Insights replication wants to be finished such that leaves zero space for blunders; in some other case, it could have an impact at the appraisal arrange. It's far fundamental to make the looking, sharing, carport, switch, assessment, and perception of that data as effectively as suitable [17].

The handiest method to remark on those requesting conditions is to region into effect ensuing period age which can likewise are anticipating a trouble sooner than it reasons many harm. Extortion location examples, encryptions, and well answers are tremendously essential to battle aggressors. Simultaneously, it's miles your commitment to possess your insights and save it secured at your give up at the equivalent time as searching out modern business knowledge arrangements that could guarantee a steady ROI as appropriately.

\section{CONCLUSION}

Presently multi day, huge data is one of the greatest basic rising innovations. $4 \mathrm{v}$ 's of enormous records makes the data control and investigation requesting conditions for the customary measurements stockrooms. Various scientists verified that distributed computing is a top notch vehicle for net site facilitating enormous insights remaining burdens. In any case, running on gigantic information inside the cloud has its central goal of accommodating opposing format principles. 


\section{International Journal of Engineering Applied Sciences and Technology, 2019 \\ Vol. 4, Issue 4, ISSN No. 2455-2143, Pages 100-104 \\ Published Online August 2019 in IJEAST (http://www.ijeast.com)}

Coordinating huge data with distributed computing innovations, gatherings and scholarly establishments may likewise have a higher way for the predetermination. The ability to store monstrous amounts of records in exact administrative work and way everything at enormous rates will bring about certainties that can manual companies and tutoring organizations in creating fast. On this paper, we examined the benchmarks, conceivable outcomes, and horrendous circumstances of the cloud and huge actualities.

\section{ACKNOWLEDGEMENT}

We thank our colleagues from Prerna College of Commerce, Nagpur who provided insight and expertise that greatly assisted the research, although they may not agree with all of the interpretations/conclusions of this paper.

We thank Dr. Debasis Das, Assistant Professor, Prerna College of Commerce for assistance with Big Data Concept, for comments that greatly improved the manuscript.

We would also like to show our gratitude to the Principal of Prerna College and VMV College for sharing their pearls of wisdom with us during the course of this research for their comments on an earlier version of the manuscript, although any errors are our own and should not tarnish the reputations of these esteemed persons.

\section{REFERENCES}

1. Changqing Ji, Yu Li, Wenming Qiu, Uchechukwu A., Keqiu Li, (2012) "Big Data Processing in Cloud Computing Environments", IEEE.

2. Nurmi D., Wolski R., Grzegorczyk C., Obertelli G., Soman S., Youseff L., and Zagorodnov D., (2009) "The eucalyptus open-source cloud-computing system," in Cluster Computing and the Grid, 2009. CCGRID'09.9th IEEE/ACM International Symposium on. IEEE, on (Pg124-131)

3. Riaz K., "Big data and Cloud Computing Challenges", bigdata-madesimple.com

4. Mell P., Grance T., (2011) "The NIST Definition of Cloud Computing".

5. Figure 1 (image source: https://en.wikipedia.org/ wiki/ Cloud_computing\#/media/File:Cloud_computing.svg

6. Zhang Q., Cheng L., Boutaba R., (2010) "Cloud computing: state-of-the-art and research challenges".

7. Sasikala P., (2013) "Research challenges and potential green technological applications in cloud computing." International Journal of Cloud Computing, 2(1), (Pg1-19).

8. Katal A,, Wazid M., and Goudar R. H., (2013) "Big Data: Issues, challenges, tools, and Good practices.". Noida: (Pg404-409).

9. Douglas and Laney, (2008) "The importance of 'Big Data': A definition,".
10. Xindong W., Xingquan Z., Gong-Qing W., Wei D., (2014) "Data Mining with Big Data".,

11. http://www-01.ibm.com/software/data/bigdata/, IBM, (2012), "IBM What Is Big Data: Bring Big Data to the Enterprise,".

12. http://www.cloud.asperasoft.com, "Enabling cloud computing \& storage for Big Data applications with ondemand, high-speed transport, Taking Big Data to the Cloud".

13. Changqing J., Yu L., Wenming Q., Uchechukwu A., Keqiu L., (2012), "Big Data Processing in Cloud Computing Environments", IEEE.

14. Degado R., https://datafloq.com/read/opportunitieschallenges-cloud-computing-big-data/4456

15. Robinson S., (2012, 2015), "The Storage and Transfer Challenges of Big Data.Accessed", http://sloanreview.mit.edu/article/the-storage-andtransfer-challenges-of-big-data/.

16. Chen J., Chen Y., Du X., Li C., Lu J., Zhao S., and Zhou X.., (2013), "Big Data Challenge: A Data Management Perspective." Frontiers of Computer Science 7 (2) (Pg157-164).

17. Chen M., Mao S., Zhang Y., and Leung V. C.. (2014), "Chapter 1, Big Data: Related Technologies, Challenges, and Future Prospects", Heidelberg: Springer.

18. Figure 2 (image source: https://bigdata .iexpertify.com) 